Journal of Research in Technical Careers December 2019, Vol. 3, No. 2.

(C) Author(s)

\title{
Planned Behavior Typologies of Agricultural Education Teacher Educators Regarding Service Learning as a Method of Instruction: A National Mixed Methods Study
}

\author{
Richie Roberts ${ }^{\mathrm{a}}$, M. Craig Edwards ${ }^{\mathrm{b}}$, Toni A. Ivey ${ }^{\mathrm{b}}$ \\ ${ }^{\mathrm{a}}$ Louisiana State University, ${ }^{\mathrm{b}}$ Oklahoma State University
}

\begin{abstract}
This study sought to understand the service-learning beliefs and intentions of agricultural education teacher educators. We collected quantitative data through a web-based survey instrument and course syllabi. Variables yielding statistically significant relationships were analyzed using cluster analysis, which produced three unique clusters operationalized as typologies representing the planned behaviors of teacher educators regarding service learning. For example, the Optimistically Unaware expressed positive beliefs about the method, but did not understand how to integrate service learning in their teaching methods courses. Meanwhile, the Policy-Focused Decision Makers used established education policy as anchors when navigating decisions, such as whether to feature service learning in their courses. Service-Learning Implementers espoused strong beliefs about the method's potential while also emphasizing how it could be used to enrich the preparation of agriculture teachers. Results point to the potential service learning holds if integrated as a complement to teacher preparation rather than an addition to current practice.
\end{abstract}

Keywords: cluster analysis, service learning, teacher education, typology development

\section{Introduction and Review of Literature}

The emergence of service learning (SL) as an instructional approach in higher education is a relatively recent phenomenon. However, this instructional method has deep philosophical roots that can be traced to some of the earliest origins of formalized learning and education (Speck \& Hoppe, 2004), especially in agricultural education (Roberts \& Edwards, 2015, 2018). Although thought leaders have championed different teaching methods, curricula, and philosophical positions, their views often converge around the notion that education should be used to foster social harmony and improve society (Fraser, 2014; Tyack, Lowe, \& Hansford, 1984). For example, early scholars argued that education could be used to improve students' morals, character, and virtues (Rhee, 2012). In a similar way, educators who integrate service learning into their courses frequently seek to advance 
students' morality, self-concept, and benevolence so they may more intimately understand the world's issues and problems (Crews, 2002; Eyler \& Giles, 1999), with aspirations to address such challenges.

Although difficult to define, service learning is described as a form of reciprocity in which students extend classroom learning into society to resolve communal problems while also accruing distinct benefits for all members (Bringle \& Hatcher, 1995). During the past two decades, numerous advancements in higher education regarding service learning have catalyzed the method's adoption and use (Butin, 2006, 2010; Cipolle, 2010). For example, involvement in Campus Compact, a national coalition of postsecondary education institutions with a mission calibrated toward service, has soared past 1,100 committed campuses nationwide (Campus Compact, 2016). Yet despite service learning's successes, Saltmarsh and Hartley (2008) suggested the movement had "stagnated and dissipated," especially concerning its ability to bring about "democratic, community-based knowledge and action” (p. 1). To this point, Butin (2006) asserted that many programs were little more than community service efforts in meaning and approach. Nevertheless, in teacher education, service learning has been championed as a way to help preservice teachers gain valuable practical experiences while also making contributions to local education systems and to their surrounding communities (Barnes, 2016; Hildenbrand \& Schultz, 2015). In addition, teacher education programs have begun to place more emphasis on introducing preservice teachers to instructional methods intended to facilitate higherorder thinking, collaborative learning, as well as the acquisition of skills to address ambiguous and complex social problems (Yang, Chang, \& Hsu, 2008). Because service learning as a method of instruction is positioned to assist in achieving such outcomes, it has received growing attention in teacher preparation programs (Ball \& Geleta, 2012; Chambers \& Lavery, 2012; Hart \& King, 2007). Nonetheless, many instructors struggle with the ambiguities they perceive inherent to using service learning and instead choose to exercise more teacher-centric approaches in their practice (Yang et al., 2008).

Proponents interested in using service learning for teacher education have begun to consider integrating the method into teacher preparation by exploring faculty members' beliefs and intentions (Ball \& Geleta, 2012; Bates, 2009; Hou, 2010; Tatebe, 2013). Supporters of this integration assert service learning is a way to instill professional and ethical core values (Anderson, 2000), to foster enhanced student meaning-making when solving complex problems (Lake \& Jones, 2008), and to improve teachers' efficacy for working with diverse populations (Daniels, Patterson, \& Dunston, 2010). However, Hildenbrand and Schultz (2015) expressed concerns regarding the lack of evidence to support the claim that service learning should be used and highlighted as a method of instruction in teacher preparation programs. Examples of obstacles to service learning's widespread adoption in teacher education include difficulties with attaining service sites, addressing challenges to upholding state and national teacher education standards, and juggling an already robust curriculum (Anderson \& Pickeral, 1998). Attempts to understand teacher educators' beliefs and intentions regarding the use of service learning in agricultural education have received scant attention from researchers. Therefore, this question lingers: Do agricultural education teacher educators' beliefs and intentions support the use of service learning as a method of instruction? 


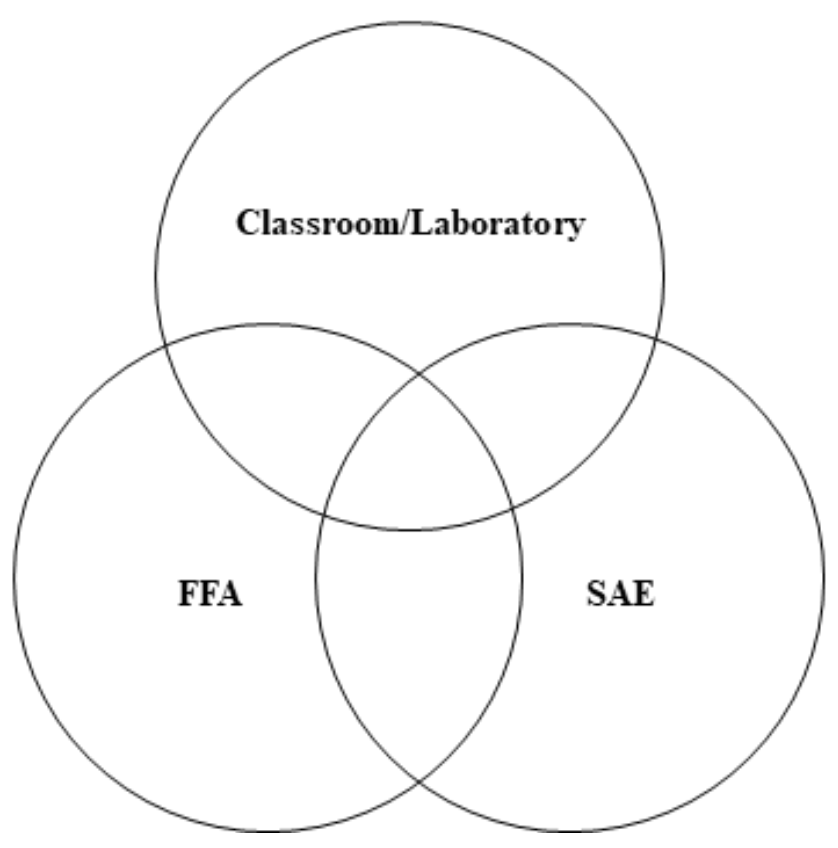

Figure 1. A visual depiction of agricultural education's comprehensive, three-circle model. Adapted from "Development of the integrated three-component model of agricultural education” by D. B. Croom, 2008, Journal of Agricultural Education, 49(1), p. 111.

Roberts and Edwards $(2015,2018)$ touched on this issue by calling for more focus on service learning in teacher preparation programs supporting agricultural education. Nevertheless, little attention appears to have been devoted to increasing its use. The problem is further complicated if considering the various characteristics and roles that school-based, agricultural education (SBAE) teachers must fulfill to be considered effective (Jenkins III \& Kitchel, 2010; Roberts \& Dyer, 2004). In SBAE, instructors are expected to facilitate learning through classroom and laboratory instruction in and about agriculture for students (National Research Council, 1988), advise students' supervised agricultural experiences (SAE) as individualized projects, and manage their participation in the National FFA Organization (FFA). An SBAE program with these components is considered a balanced or comprehensive program. See Figure 1 for a depiction of SBAE's comprehensive, three-circle model (Croom, 2008) for program delivery.

\section{Statement of the Problem}

More research is needed to distill the beliefs and intentions that presage, inspire, and enable agricultural education teacher educators to use service learning as an instructional method in their teacher preparation courses (a) to facilitate the learning of 


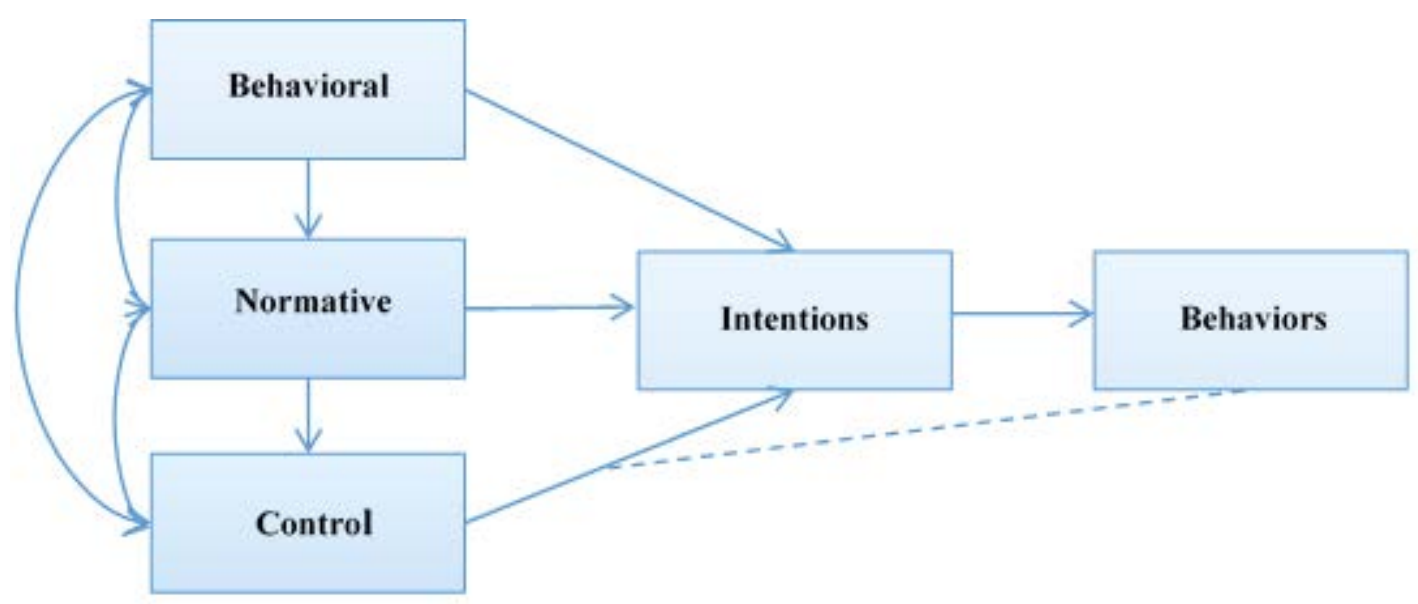

Figure 2. The theory of planned behavior. Adapted from "The Theory of Planned Behavior" by I. Ajzen, 1991, Organizational Behavior and Human Decision Processes, 50, p. 182. Copyright 1991 by Academic Press, Inc.

preservice students and (b) with the intention of students acquiring service learning as a teaching method to use as inservice teachers. This insight may yield important new understanding of the behaviors influencing how service learning is conceptualized and practiced in SBAE.

\section{Theoretical Framework}

This study was grounded in Ajzen's (1991) theory of planned behavior (TPB). Through this lens, an individual's behavior is shaped by his or her underlying intentions (Ajzen, 2006). However, Ajzen (1991) theorized that three systems of belief foreground an individual's intentions: (a) behavioral (attitudes), (b) normative (subjective or social norms), and (c) control (perceived behavior controls). Behavioral beliefs, or attitudes, refer to the perceptions individuals' have regarding the consequences of particular behaviors; therefore, these perceptions influence the formation of positive or negative attitudes (Ajzen, 2006). If their attitudes toward given behaviors are favorable, individuals are more likely to engage in such, and the counterfactual is also more likely to occur. On the other hand, normative beliefs, or subjective norms, represent the degree of social pressure individuals recognize, which influence their adoption or rejection of behaviors (Ajzen, 2002). Finally, control beliefs, or perceived behavioral controls, are related to the levels of difficulty individuals perceive associated with implementing or exercising behaviors. A change in one or more of these belief systems is theorized to influence whether individuals intend to execute specific behaviors in the future (Francis et al., 2004). Figure 2 provides a visual representation of Ajzen's (1991) TPB. 
By using Ajzen's TPB as our theoretical lens, we operationalized four key variables for this study: behavioral beliefs, normative beliefs, control beliefs, and intentions. Descriptions for how each variable were measured in this study are provided below:

1. Behavioral beliefs: teacher educators' perceived benefits of using service learning in their classrooms and communities;

2. Normative beliefs: the barriers teacher educators perceived within their respective institutions;

3. Control beliefs: teacher educators' perceived barriers to employing service learning in their classrooms;

4. Intentions: as interpreted by the extent service learning was integrated into teacher educators' course syllabi designed to feature instruction on various teaching methods.

As such, this investigation sought to describe the educators' beliefs and intentions about service learning as a method of instruction in their teaching practice and in that of students preparing to be teachers of SBAE. This aim guided development of the study's purpose and research question.

\section{Purpose and Research Question}

This mixed methods study sought to understand the service learning beliefs and intentions of agricultural education teacher educators. By using Ajzen's (1991) TPB as a theoretical lens, one research question guided the portion of a larger investigation reported on here: How did the study's qualitative findings help explain its quantitative patterns?

\section{Methodology and Procedures}

This study used an explanatory, sequential mixed methods design by which priority was assigned to the qualitative strand, i.e., Quan $\rightarrow$ QUAL (Creswell \& Plano Clark, 2011). Relying on a pragmatist lens (Morgan, 2007), phase one was the collection of quantitative data by employing Dillman's, Smyth's, and Christian's (2014) tailored survey design procedures to gather such through a web-based instrument using Qualtrics online software. The participants also submitted course syllabi, which were quantized during analysis using the Service-Learning Syllabus Analysis Guide [SLSAG] (Gelmon, Holland, Driscoll, Spring, \& Kerrigan, 2001). Cluster analysis procedures were followed (Macia, 2015) to identify patterns resulting from the quantitative findings. Cluster analysis allows researchers to categorize individuals using a combination of relevant variables. The combination of variables used for clustering was determined by mobilizing those yielding statistically significant relationships $(p<.05)$ with the dependent variables (Mooi \& Sarstedt, 2011). Thereafter, as determined by cluster analysis, we interviewed nine agricultural education teacher educators who provided qualitative data supporting the creation of typologies - a procedure that evoked rich meaning from the members of each cluster. The study's design procedures and related products are displayed in Figure 3. 

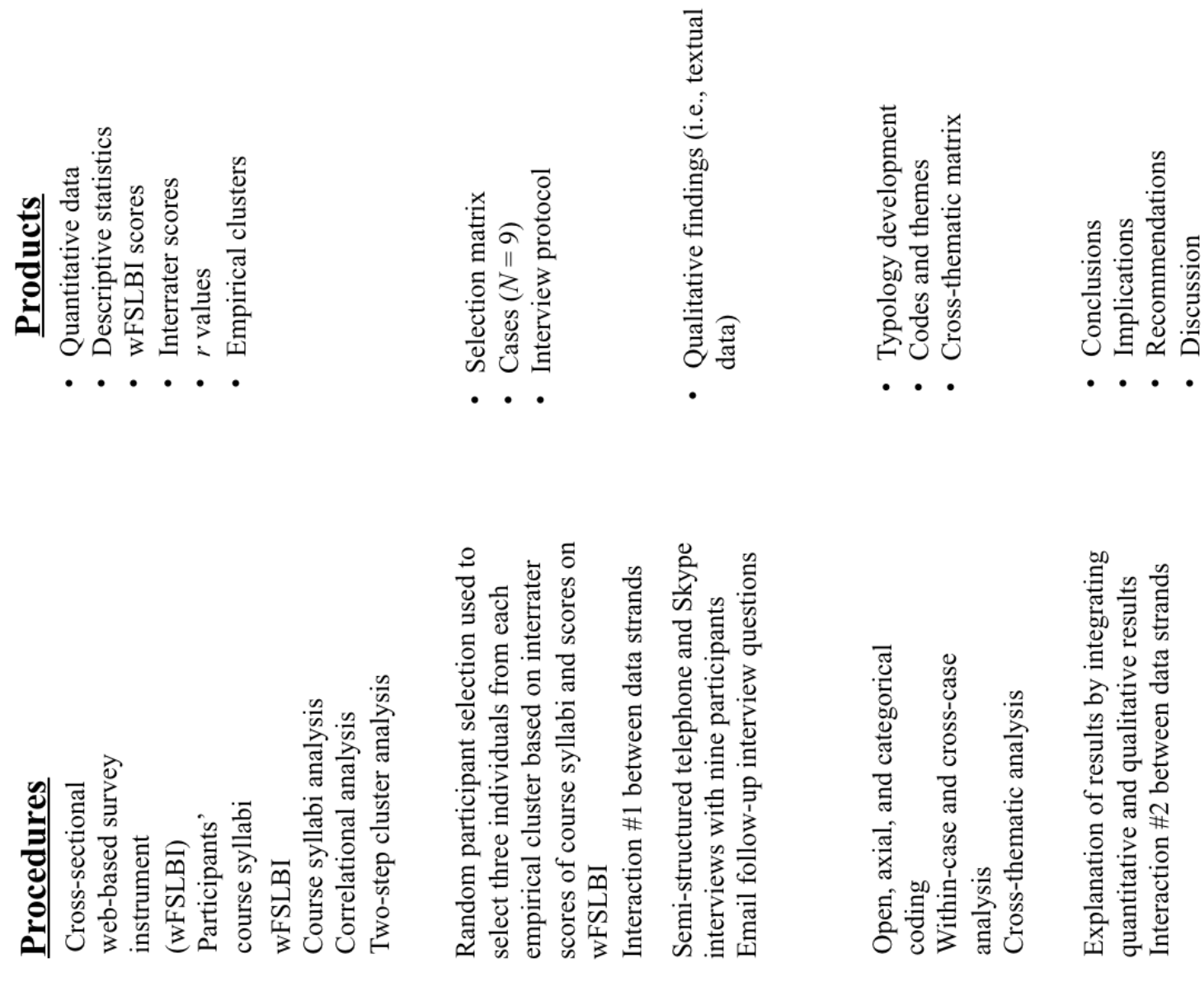

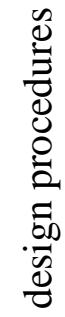

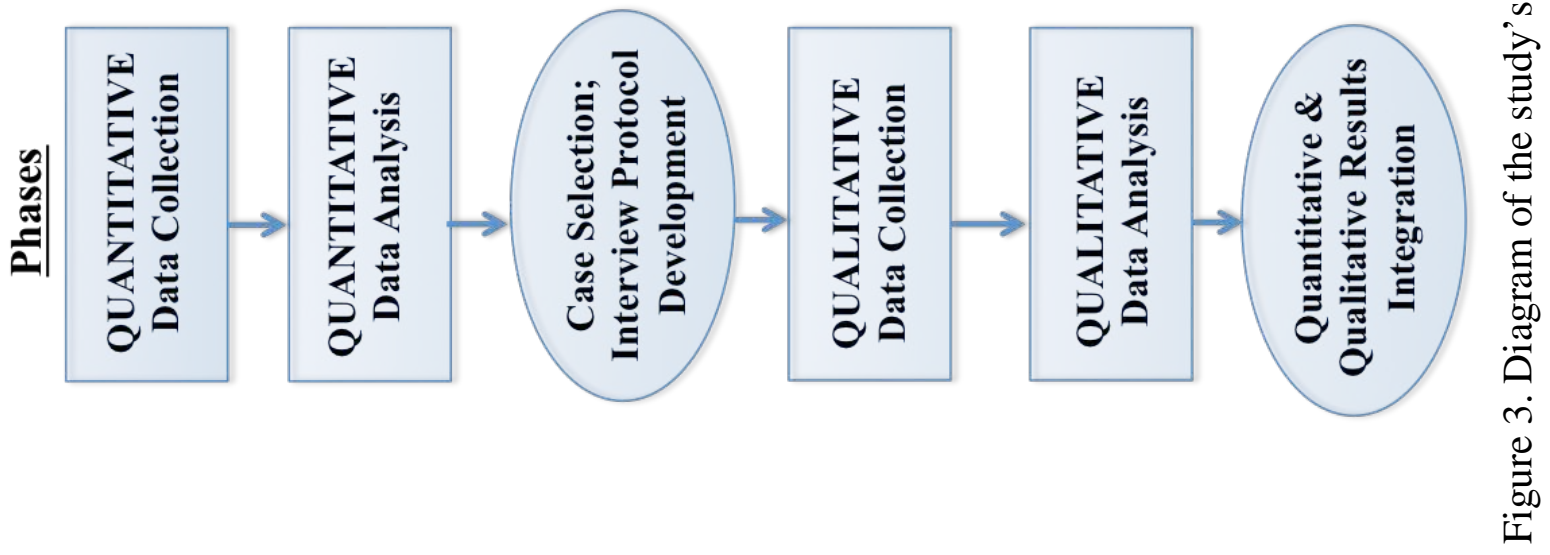


Reflexivity. Engagement with the data changed based on phase of the study. As such, it is important to reveal our previous experience and biases. For instance, two of the researchers previously served as SBAE instructors in their respective home states, and the third was a science teacher. Further, the lead researcher had used service learning to improve student learning outcomes and the method serves as his primary line of inquiry. It also bears noting that we had interacted with participants in this study at research conferences and through other professional venues. Therefore, these relationships may have influenced some individuals to participate in the study as well as what they chose to share in their responses.

During the qualitative phase, we developed cordial relationships with participants through the qualitative interview sessions. As a consequence, each of these experiences created additional opportunities to introduce bias as well as result in misinterpretations of the study's findings. We, therefore, placed particular emphasis on triangulating sources, verification procedures, member checks, investigating the disconfirming evidence, and establishing inter-rater reliability to increase the likelihood of accurate results. To provide more insight into these techniques, we described our methodological decisions and choices separately for the study's quantitative and qualitative phases. It is also important to disclose that gift card incentives were used to recruit participants for the study.

Phase I: Participant Recruitment, Quantitative Data Collection, and Instrumentation. The population was a census of agricultural education teacher educators who were active members of the American Association for Agricultural Education (AAAE). Therefore, the frame for this study was AAAE's membership directory, as maintained by its membership secretary (AAAE, 2016). However, instructors who were not members of AAAE could also teach methods courses that include aspects of service learning; therefore, the possibility of coverage error existed (Dillman et al., 2014). More than 80 higher education institutions in the United States prepare SBAE instructors (Birkenholz \& Simonsen, 2011). To ensure the population of interest was identified, we administered a web-based instrument packet (Dillman et al., 2014), after IRB approaval, through the AAAE electronic mail listserv. The participants were asked to indicate whether they taught at least one agricultural education teaching methods course either during the three previous academic years or would do such in the spring academic term of 2017. This criterion was used as a sorting variable to determine the eligibility of participants regarding who should complete the survey instrument. Individuals who met the criterion were allowed to continue to the remainder of the instrument's items and submit a course syllabus; other respondents were not permitted to continue. In total, 77 agricultural education teacher educators responded to the online survey instrument, resulting in 46 useable responses (59\%) with 43 institutions represented.

The web-based instrument had three measures: (a) personal characteristics, (b) items slightly modified from Hou's (2010) Web-based Faculty Service-Learning Beliefs Inventory (wFSLBI), and (c) items slightly modified from the SLSAG (Gelmon et al., 2001). Reported findings are part of a larger data set. Results from quantitative measures are not featured here but were used to demonstrate the quantitative strand's role in the 
development of typologies. The study's primary quantitative measure, the wFSLBI, was designed to understand faculty members' service learning beliefs and is grounded theoretically in Ajzen's (1991) TPB. Through factor analysis procedures, Hou (2010) confirmed four distinct factors: (1) perceived benefits at the classroom level (PROS_CLS) with seven items, (2) perceived benefits at the community level (PROS_COMM) with six items, (3) perceived barriers at the classroom level (CONS_CLS) with four items, and (4) perceived barriers at the institutional level (CONS_INST) with three items (Hou, 2010). All items for the wFSLBI were reported using a five-point, Likert-type scale. Post hoc reliability estimates for each of the instrument's four subscales were .71 or larger and considered acceptable (Field, 2013).

We used the SLSAG (Gelmon et al., 2001) to analyze agricultural education teacher educators' intentions in regard to service learning, as demonstrated in their course syllabi. The SLSAG was used to examine the extent to which educators intended to incorporate indicators of high-quality service learning in their course syllabi. Although syllabi formats vary among universities and individual faculty members, Gelmon et al. (2001) argued that if intentions to feature service learning in a course exist, such should be reflected in the instructors' learning objectives, academic activities, and learning assessment strategies. Accordingly, the SLSAG features 10 key indicators, called evaluative items, regarding the extent to which instructors integrated service learning in their course syllabi (Gelmon et al., 2001). All 46 participants submitted course syllabi. A training session for the syllabi raters was conducted to establish interrater reliability in which two external raters and the lead researcher scored participants' course syllabi (Bornmann, Mutz, \& Daniel, 2010). Thereafter, each rater scored a randomly selected syllabus to identify scoring differences so recommendations could be provided to improve consistency among the raters. Finally, raters individually assigned a " 1 " for each of the 10 evaluative items on the instrument if the syllabus contained the service learning element and a " 0 " if it did not. Interrater reliability analysis yielded an interclass correlation coefficient (ICC) of .88, which was considered satisfactory (Whitehurst, 1984).

Inter-Phase: Clustering Procedures and the Identification of Qualitative Cases. We analyzed quantitative variables that yielded statistically significant relationships $(p<.05)$ through cluster analysis procedures (Macia, 2015). Thereafter, a two-step cluster analysis approach was used rather than hierarchical or k-means because the variables of interest were a combination of ordinal and nominal data derived from different scales (Chiu, Fang, Chen, Wang, \& Jeris, 2001). Each variable, therefore, was standardized before initiating clustering procedures. In the first stage, homogenous clusters were formed based on their rankings (Chiu et al., 2001). After the first iteration, eight clusters were generated. Next, clusters were discriminated, and reduced, based on predictor importance (Mooi \& Sarstedt, 2011). Through this technique, three high-quality clusters were identified. Across clusters, predictor importance included participants' (a) service-learning experiences in postsecondary education, (b) service-learning teaching experiences, (c) intentions, (d) service-learning experiences in secondary education, as well as (e) their perceptions of service learning regarding CONS CLS, PROS CLS, CONS INST, and PROS COMM. The three clusters were operationalized as bounded cases for qualitative analysis (Stake, 2006). 
Phase II: Qualitative Data Collection, Analysis, and Typology Development. In the qualitative phase, we used a multiple case study approach (Stake, 2006) to develop and define typologies. The emphasis in the qualitative strand was placed on achieving representativeness (Teddlie \& Yu, 2007). Therefore, we selected three qualitative cases from each cluster using random selection - an approach that is rare but acceptable in qualitative inquiry (Miles, Huberman, \& Saldaña, 2014). We randomly selected participants 41, 44, and 46 of the first cluster, participants 9, 20, and 39 in the second cluster, and participants 13, 24, and 26 from the third cluster. As such, nine teacher educators participated in 45 to 60 minute, semi-structured telephone or Skype interview sessions (Creswell \& Plano Clark, 2011). Thereafter, each qualitative interview was transcribed verbatim by the lead researcher.

Due to the importance of representing occurent differences and nuances, random selection provided the best opportunity to portray a rounded perspective of each cluster. By using these procedures, the quantitative strand of data offered a general silhouette of the phenomenon and the qualitative strand provided a more detailed, granular depiction. It also should be noted that interaction between the two strands occurred at two different points during the study: quantitative data analysis and integration of the results. For example, the first interaction took place when we used the quantitative clusters to select the qualitative cases (Macia, 2015). Further, the investigation was sequentially structured to occur in a successive way; thereby, the quantitative findings could be used as a guide for developing the interview protocol to gain a richer, multi-layered understanding of participant views (Creswell \& Plano Clark, 2011). As such, the mixing of strands occurred at the study's design level through clustering procedures (Creswell \& Plano Clark, 2011; see Figure 3). In addition, the integration of both data strands was achieved when the qualitative findings were used to determine cluster membership. Next, we describe how our data analysis unfolded.

Qualitative Data Analysis. We used qualitative analysis software NVivo to manage and explore the data. Initial data analysis was conducted using the constant comparative method, which was facilitated through three coding types: open, axial, and selective (Corbin \& Strauss, 2015). Open coding required that the data units be grouped into distinct categories. Axial coding necessitated that we scrutinize relationships among categories to develop evidentiary warrants (Saldaña, 2012). We then used selective coding to create an analytic storyline of the data. As a result, our assertions for typology generation were built up to narrate the multiple views presented in each cluster (Corbin \& Strauss, 2015). Through case comparisons and contrasts, we chose to operationalize the clusters as typologies by weaving the voices of within-case participants into rich descriptions (Stake, 2006). To that end, the second interaction between the strands occurred as quantitative and qualitative data were integrated during the discussion of results (Figure 3).

Qualitative Rigor and Trustworthiness. Lincoln's and Guba's (1985) four criteria for qualitative quality - credibility, confirmability, transferability, and dependability - drove our ethical decision making in this study. To achieve this, we triangulated findings using multiple forms of data, provided context-rich descriptions, and 


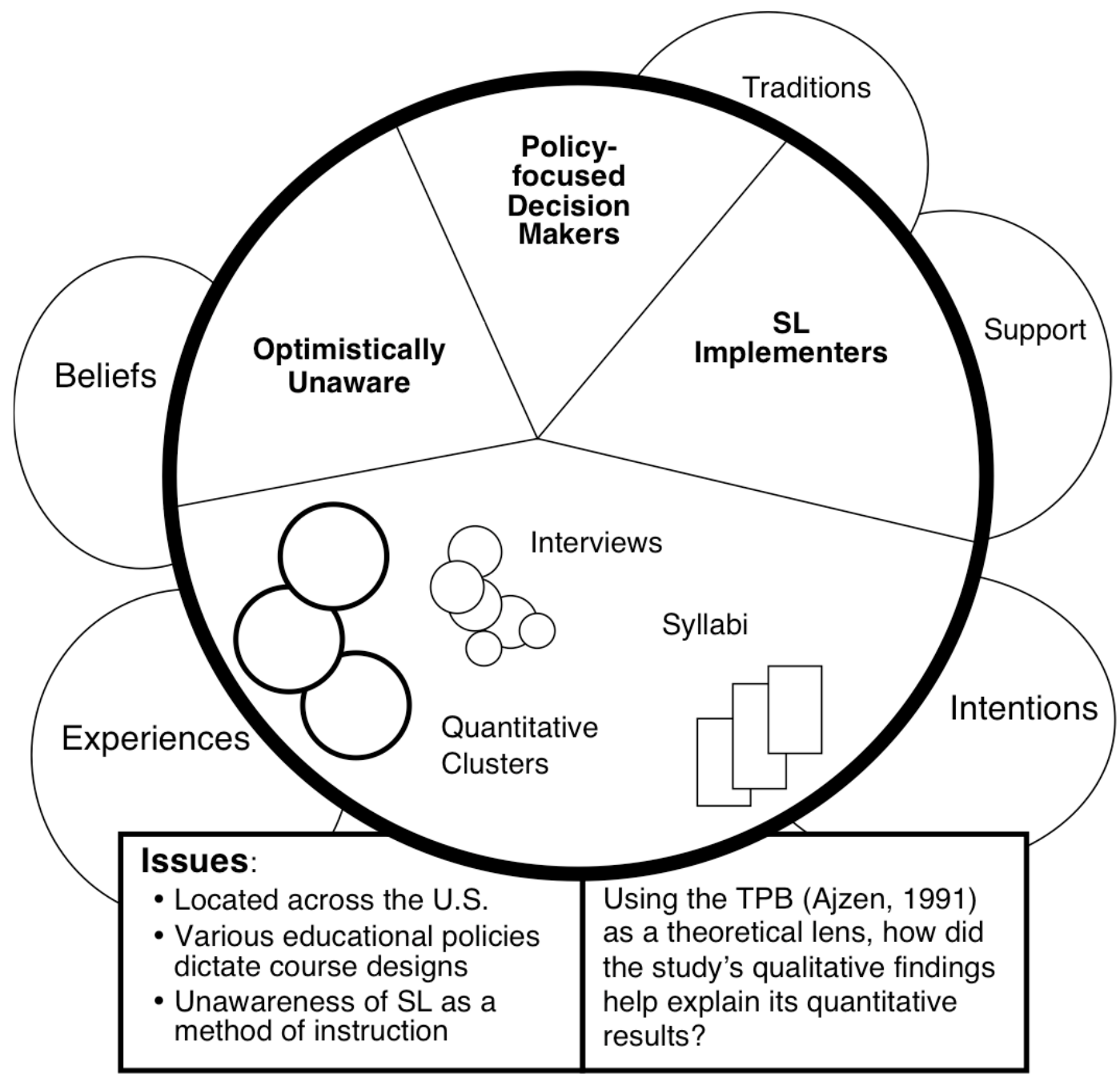

Figure 4. Emergent qualitative design of the study. Adapted from Multiple Case Study Analysis (p. 19), Stake, R. E, 2006, New York, NY: The Guilford Press

identified emergent uncertainties (credibility); we were also explicit about our decisions, biases, and other influences by providing detailed descriptions of methods and procedures as well as mobilizing rival conclusions (confirmability) (Lincoln \& Guba, 1985). Further, we sought a theoretically diverse sample, described participants' personal and professional characteristics, and linked findings to existing theory (transferability); and we strove to conduct an investigation that was stable and consistent with the traditions of qualitative inquiry while being transparent about our role in the study (dependability) (Lincoln \& Guba, 1985). 


\section{Findings}

After analyzing the qualitative data through case comparisions, we operationalized the clusters as typologies (Stake, 2006). Predictors from the quantitative clusters were also considered as a guiding interpretive tool. The three typologies identified through cluster analysis procedures represent the planned behaviors (Ajzen, 1991) of agricultural education teacher educators regarding service learning as a method of instruction: (a) Optimistically Unaware, (b) Policy-Focused Decision Makers, and (c) Service-Learning Implementers. It is important to note that no typology is considered better or more correct in regard to conceptualizing or delivering teaching methods courses in agricultural education. A description of each typology is offered below along with supporting themes, which are grounded in Ajzen's (1991) three belief systems: behavioral, normative, and control. A visual depiction of the qualitative strand's emergent design is displayed in Figure 4.

Typology \#1: Optimistically Unaware. The Optimistically Unaware participants expressed positive beliefs about the potential of service learning. In addition, the three educators interviewed were familiar with the term "service learning," and two had experience with the method at the secondary school level. However, the Optimistically Unaware explained they did not fully understand how to integrate or feature the method in their teaching methods courses within existing design structures. For example, when describing the challenges of service learning, participant 44 revealed that one challenge was "not completely understanding it [service learning] myself.” Despite this unawareness, the interview participants were optimistic about using the method in the future. At the conclusion of interview sessions, for instance, all three described intentions to put more thought into including service learning in their teaching methods courses going forward. Participant 46 revealed:

I'm not doing a great job of even talking about service learning in my preservice coursework, so this is something, as I'm thinking, I'm reflecting on my own practice and thinking, "man, I need to." That is definitely something I would agree 100 percent that we ought to be doing that.

Therefore, given the backgrounds of the Optimistically Unaware, their beliefs and intentions were presented through a lens of projection, i.e., largely experience and contextfree, but looking toward using service learning in future semesters.

Behavioral Beliefs. Two sub-themes explained the Optimistically Unaware's behavioral beliefs (Ajzen, 1991): (a) experiential learning and (b) service learning's benefit to SBAE's comprehensive, three-circle model (see Figure 1).

Experiential learning. Each participant belonging to the Optimistically Unaware typology articulated that they saw value in service learning because of its experiential approach. They explained that teaching experientially could help bring the curriculum to life by making learning more permeable in which the walls separating classrooms and the real-world could be diminished. Participant 44 explained: "Hands on anything is always a 
positive. And I think that service learning has potential to actually put them [students] in those real-world situations."

Service learning's benefits to SBAE's comprehensive, three-circle model. Although the Optimistically Unaware did not appear to have put much deep philosophical thinking into using service learning as a method of instruction, they articulated ways the method might benefit each component of SBAE's comprehensive, three-circle model. For example, describing service learning's role in SBAE, participant 41 highlighted the ways in which SBAE teachers were using service learning through classroom activities in her home state. She elaborated: "Yesterday afternoon [I visited] a meat laboratory, the hams and bacon that [did not] get bought [were] donated to the local food bank."

Normative Beliefs. Receiving support from individuals of influence is critical to forming intentions of planned behavior - a concept Ajzen (1991) called normative beliefs. Therefore, in this study, normative beliefs refer to whether participants perceived their institutions' leaders encouraged the use of service learning. Overall, participants reported a supportive institutional culture regarding service learning. Participant 44 even suggested that his institution might look favorably on using service learning in the tenure and promotion process: "In the teaching portion of our P\&T packet, there is a place where it asks not just for like your normal coursework or anything like that, [but also] other teaching experiences and I think you could highlight service learning.”

Control Beliefs. How individuals view the perceived challenges of an endeavor is critical in the formation of their control beliefs (Ajzen, 1991). As such, participants in this study considered their personal challenges as well those that preservice teachers might face in regard to implementing the method. To this point, the Optimistically Unaware's control beliefs emerged through two subthemes: lack of understanding and time.

Lack of understanding. The most consistently reported barrier from the Optimistically Unaware typology was the lack of understanding of service learning. For example, the participants perceived that neither they nor others in agricultural education fully understood the difference between service learning and community service. And, as a consequence, opportunities for using service learning were not fully realized. Participant 41 explained: "I think there's something going on [with service learning but] they [SBAE teachers] just don't know what it is.”

Time. Acknowledging the challenge of overwhelming time commitments when conducting quality service-learning projects also arose as a core control belief. Participant 44 elaborated: "I think the time [required is an issue]; time is definitely a barrier to doing these type[s] of service-learning things.” Although the Optimistically Unaware participants recognized the advantages of service learning, their lack of understanding and perceptions of time constraints seemed to inhibit their adoption of the method. Nevertheless, they were optimistic about service learning's potential as a method of instruction in SBAE.

Typology \#2: Policy-Focused Decision Makers. The second typology included educators with service learning experience as students and teachers. This typological group expressed that service learning had the potential to improve the lives and educational 
experiences of students, teachers, and community members. However, their intentions concerning the use of service learning varied considerably. Through analysis of these discrepancies, the second planned behavior typology emerged as teacher educators who were Policy-Focused Decision Makers. Adherence to existing policies appeared to distinctly influence the ways in which participants 9, 20, and 39 structured their teaching methods courses and whether they chose to integrate service learning as a method of instruction. For example, participant 39 explained:

I mentioned some of the educational policy in the state we are in, the program called [Blinded]. So I don't want it to seem like I'm only griping about that. But right now it is always on the forefront of our minds.

When considering the findings, it is imperative to understand that the PolicyFocused Decision Makers' experiences, beliefs, and intentions often supported the use of service learning as a method of instruction. However, intervening education policies drove the degree to which they incorporated the method in their teacher preparation courses. This ought versus is conundrum is presented through a discussion of Ajzen's (1991) three belief systems: behavioral, normative, and control.

Behavioral Beliefs. The Policy-Focused Decision Makers expressed largely positive and encouraging views concerning the benefits of service learning as a method of instruction. Existing attitudes within this typology, therefore, supported the use of service learning - a notion connected to behavioral beliefs (Ajzen, 1991). Two distinct subthemes emerged uniformly through data analysis: service learning's benefits to SBAE's comprehensive, three-circle model and the personal development of students.

Service learning's benefits to SBAE's comprehensive, three-circle model. While articulating the advantages that service learning may offer agricultural education, the Policy-Focused Decision Makers noted the method could assist instructors with delivering SBAE's comprehensive, three-circle model. In support, participant 39 described how his ideal three-circle model would include a service learning component. He opined: "Ideally if you had [a] paintbrush, [being] the paint guy, you want a program that's going to be meant for service learning with all three circles being equal.”

Personal development of students. Each of the Policy-Focused Decision Makers' interviews mentioned the transformative potential that service learning could offer students. Participant 9 explained how service learning might be used to help students adopt a more accepting and change-focused worldview. She elaborated: "[I]t's so critical that students think past our own very small individual universe and think about that whole idea of tithing, in the big sense not religious, but giving back." Therefore, the teacher educators appeared to perceive the method could help their students grow profoundly in meaningful ways.

Normative Beliefs. Ajzen (1991) referred to normative beliefs as views influenced by individuals and forces deemed important within a given social system. For the PolicyFocused Decision Makers, these beliefs surfaced as conflicted yet distinguishing features. Two subthemes provided the basis for this interpretation: policies as decision anchors and 
supportive institutional cultures.

Policies as decision anchors. Although Policy-Focused Decision Makers expressed positive views about service learning, their intentions were diverse in regard to integrating the method into their teaching methods courses. After reflecting on the participants' perspectives, the belief that policy served as their decision anchors emerged. For example, when conceptualizing courses, individuals comprising this typology appeared to consult existing policies to decide which teaching methods, assignments, and projects held the most value for their students. In the case of participant 20, she explained that "[e]verything goes through the teacher education committee. They're a governing body of the education division. I have the freedom to do some things, but something that affects the portfolio of those students, I don't have that authority."

Supportive institutional culture. Participants 9, 20, and 39 articulated that their campuses largely promoted a culture in which service learning was encouraged. For example, all reported having an office of service learning, institutional missions that addressed the need for the method, as well as the provision of service learning-related professional development opportunities on their campuses. Participant 39 elaborated: "My university requires each college to have service learning in their classes. In our university catalog, some courses are designated as a service-learning course.”

Control Beliefs. Control beliefs of the Policy-Focused Decision Makers, i.e., their perceptions of how easy or difficult a behavior may be to implement, were related to the issue of time. Participant 20 contended: "The biggest thing is time.” The teacher educators explained that SBAE instructors in their home states had many job duties and, therefore, little temporal space existed in which to implement what they perceived to be a timeconsuming method of instruction. The Policy-Focused Decision Makers had significant experience with service learning as a method of instruction; however, existing education policies appeared to shape the degree to which they chose to integrate service learning in their teaching methods courses.

Typology \#3: Service-Learning Implementers. Members of the third cluster, Service-Learning Implementers, espoused strong beliefs about the method's potential while also emphasizing how it could be used to enrich agricultural education teacher preparation. The Service-Learning Implementers articulated their beliefs and intentions (Ajzen, 1991) regarding service learning by reflecting on prior related teaching experiences rather than projecting what the method of instruction might achieve. Service-Learning Implementers had experiences with the method as students and teachers and voiced intentions to continue to use the method in their practice. Therefore, it was a memory framework (Linde, 2009) from which participants 13, 24, and 26 consulted their salient experiences to occasion and narrate behavioral beliefs, normative beliefs, and control beliefs regarding service learning as a method of instruction.

Behavioral Beliefs. Emerging from the data corpus were Service-Learning Implementers' richly storied and temporally marked illustrations of their behavioral beliefs: service learning as a complement to teacher education; service learning's role in 
SBAE's comprehensive, three-circle model; and the personal development of students.

Service learning as a complement to teacher education. The talk of ServiceLearning Implementers regarding the method illuminated how they used it in teacher preparation to uphold and operationalize their philosophies of teaching. For example, they revealed that using the method emboldened them to challenge their students to grapple with the complexities of teaching and learning outside the walls of university classrooms while negotiating such experiences through reflection. Participant 13 explained: "It starts to give them [my students] a halfway real perspective of what it looks like to be a teacher in a classroom."

Service learning's benefits to SBAE's comprehensive, three-circle model. The Service-Learning Implementers also elucidated the strategic advantages that using service learning could provide teachers in regard to delivering SBAE's comprehensive, three-circle model. For example, patterns of discourse converged on the notion that service learning could assist in facilitating learning experiences within and among the FFA, supervised agricultural experiences, and classroom and laboratory aspects of SBAE. When considering service learning's potential, participant 24 explained: "I think service learning plays a part in all" three dimensions of an agricultural education program. However, they also noted that challenges still had to be overcome before the method's use became more widely adopted in each of the model's three components.

Personal development of students. By design, service learning is employed to assist students with making sense of experiences while also forging deep connections regarding how their actions can create change in local communities. Participant 26 described how the method could enhance students' personal development. He explained that by partaking in acts of service, students begin to embrace a sense of "leadership" and "responsibility," which helped them adopt more mature perspectives. He maintained this maturation was visible when interacting with individuals in the community. This teacher educator further said: "By helping within the community you [, i.e., his students,] start to be looked upon as a leader and someone to go to."

Normative Beliefs. Faculty members are often influenced in their roles by institutional controls that govern existing practices, policies, and day-to-day activities. Two sub-themes undergirded the normative beliefs theme for this typology: supportive institutional cultures and professional enrichment.

Supportive institutional cultures. Each participant interviewed from the third cluster emphasized the highly supportive culture for service learning at his or her respective institution. Participant 26 stated: "We have a whole office of service-learning. We were one of the first institutions in the country to require each department to have a certain number of hours of service-learning." Other examples of assistive institutional cultures included offices of service learning on their campuses, award recognitions, professional development opportunities, designated service learning course offerings, and course credit hours for students' service-learning endeavors.

Professional enrichment. The Service-Learning Implementers also described the scholarly enrichment the method offered to their careers. For example, the participants had used the method to support their scholarly interests, while also benefitting students and 
Table 1. Cross-Case Comparison of Qualitative Findings

$\begin{array}{ccc}\text { Optimistically } & \text { Policy-Focused } & \text { Service-Learning } \\ \text { Unaware } & \text { Decision Makers } & \text { Implementers }\end{array}$

Themes

Behavioral Beliefs

- Experiential Learning

- SL's Benefits to SBAE's Comprehensive, Three-Circle Model

- Personal Development of Students

- $\quad$ SL as a Complement to Teacher Education

Normative Beliefs

- Supportive Institutional

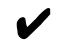

*

$\boldsymbol{*}$
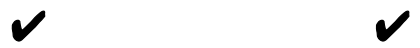

4

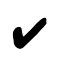

$\boldsymbol{*}$

$\boldsymbol{x}$

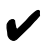

Cultures

- Policies as

Decision

Anchors

- Professional Enrichment

Control Beliefs

- Lack of Understanding

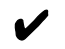

- $\quad$ Time

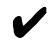

$\boldsymbol{*}$

s.

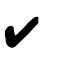

n

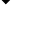

2.

$\boldsymbol{x}$

Note. Not present $=\mathbf{N} ;$ Present $=\boldsymbol{\kappa}$. 
local communities. Participant 13 elaborated: "I did just a brief poster presentation last year based on some data we collected on a couple semesters in terms of our [service learning] project."

Control Beliefs. The third theme captured Service-Learning Implementers' beliefs and experiences navigating the perceived challenges of service learning - a concept Ajzen (1991) termed control beliefs. The Service-Learning Implementers were candid about the method's downsides and collectively expressed the view that SBAE teachers must be fully committed to ensure their service learning projects are successful. The major challenge stressed by the Service-Learning Implementers was that of time. Participant 26 gave voice to this issue: "for them [students] to have extra time to go devote two or three days for a [service-learning] project is sometimes quite difficult." The Service-Learning Implementers advocated for service learning in their teacher preparation programs based on previous experiences supporting beliefs that the method could be used to complement teacher education by helping to build preservice teachers' capacities to implement it in their future practice.

Cross-Case Analysis. A cross-case analysis (Stake, 2006) of the qualitative themes revealed similarities and differences regarding the dimensions of participants' three belief systems, as theorized by Ajzen (1991). Differences among the emergent factors in the qualitative strand helped define and describe each typology distilled by the researchers. Moreover, it is critical to acknowledge that across typologies three subthemes were constant: service learning's benefits to SBAE's comprehensive, three-circle model; supportive institutional cultures: and time. Table 1 offers an overview of the cross-case comparison of the study's themes and subthemes.

\section{Conclusions}

The objective of this investigation was to understand the service-learning beliefs and intentions of agricultural education teacher educators. Findings suggest that the planned behaviors (Ajzen, 1991) of teacher educators regarding their use of service learning as a method of instruction can be interpreted through three typologies. The Optimistically Unaware explained that they did not entirely understand how to implement service learning into their teaching methods courses. Meanwhile, Policy-Focused Decision Makers' belief systems supported the use of the method; however, existing education policies influenced their decisions about whether to use service learning. The final typology, Service-Learning Implementers, articulated how they used service learning as a complement to teacher preparation. These views offer new insights on the TPB (Ajzen, 1991) as well as the practice of service learning, especially concerning the method's existing position in programs for the preparation of agricultural education teachers. Findings, therefore, not only broaden the service learning and agricultural education literature bases, but also introduce new developments for the relevance of Ajzen's (1991) TPB in understanding the pedagogical choices of teacher educators. Representatives of each typology expressed service learning's potential to serve as a delivery strategy in all 
three programmatic dimensions of SBAE: classroom and laboratory instruction, supervised agricultural experiences, and FFA (see Figure 1). Further, three common sub-themes emerged after analysis of each typology: service learning's benefits to SBAE's comprehensive, three-circle model; supportive institutional cultures; and time.

However, for the teacher educators in this study, their articulation of examples and strategies for SBAE instructors to use in facilitating service learning in students' supervised agricultural experiences was mostly tacit if not ambiguous - a finding not currently reflected in agricultural education's literature. For each typology, participants also described relatively supportive institutional cultures towards service learning. In this regard, the participants reported their institutions maintained offices of service learning, provided professional development opportunities, offered faculty awards, and, in some cases, required colleges and departments to designate service learning courses. Further, the teacher educators perceived their administrators were supportive of the method's use in teacher preparation for agricultural education. These findings align with existing service learning literature (Barnes, 2016; Butcher et al., 2003; Hart \& King, 2007), but had not been reported previously for agricultural education.

When asked to articulate the potential challenges of integrating service learning into their courses, the teacher educators identified time as a consistent barrier. The time factor was perceived as a challenge because the educators described struggling to find enough space in their courses to properly integrate and feature the method. The participants also noted that time was a barrier for SBAE instructors due to the many duties, responsibilities, and expectations associated with their jobs, which already monopolized teachers' schedules. Although time is a common barrier reported in the service learning literature (Butin, 2006; Chambers \& Lavery, 2012), it may not have received sufficient attention in preparing teachers of agricultural education to use service learning.

\section{Recommendations, Implications, and Discussion}

The development of planned behavior typologies in this inquiry appear to unsettle and expand existing conceptions of service learning in the context of agricultural education. Given these new insights, it is important to address the resulting implications for research, theory, and practice. First, future researchers should explore how teacher educators' behavioral, normative, and control beliefs (Ajzen, 1991) influence the ways they depict service learning's ability to integrate the components of SBAE's comprehensive, threecircle model (Croom, 2008; Roberts \& Edwards, 2015). Because of the rich discourse surrounding service learning, as articulated by participants in this study, more research is needed to explain how successful service-learning supervised agricultural experiences are defined and operationalized. In addition, given the emergence of the Policy-Focused Decision-Makers typology, stakeholders should also consider the ways and extent that existing education policies may stifle the use of service learning in teacher preparation courses. Because some teacher educators reported not featuring service learning as a method of instruction, future studies should investigate the implications of silencing service learning in the teacher education curriculum, and how that may negate potential outcomes for student learning as well as the transformation of SBAE programs and local 
communities in positive and meaningful ways. More research is also needed to uncover the stories that Service-Learning Implementers tell about the impacts of service learning on students and communities associated with using the method. In addition, future investigations should seek to identify which lived experiences involving service learning influence teacher educators' decisions to integrate the method into their teacher preparation courses.

Ajzen's (1991) TPB is often used as a theoretical grounding in quantitative-oriented studies (Armitage \& Conner, 2001; Chiaburu \& Tekleab, 2005; McCarthy \& Garavan, 2006). However, this study offers new understandings into ways the theory could be expanded, i.e., the development of planned behavior typologies. As such, more theorybuilding efforts should be devoted to understanding the limits and possibilities of Ajzen's (1991) TPB, especially regarding the use of service learning in agricultural education. For example, by securing a theoretical sample (Miles et al., 2014), grounded theory methods could be used to more intimately describe the influences, processes, and parameters that foreground the planned behaviors of teacher educators regarding their professional practice. This study also holds important implications for future practice. To this aim, agricultural education teacher educators should utilize the resources available at their home institutions to support them in considering how service learning could be integrated into their teaching methods courses. Perhaps these local professionals can provide valuable institutional knowledge and assets that would assist teacher educators in traversing the various policies and scheduling issues appearing to influence their underlying intentions about using service learning as a method of instruction. In addition to using local resources, professional development opportunities also should be incorporated at regional and national AAAE conferences- to demonstrate how service learning can be used in teaching methods courses and in other contexts. During these professional development opportunities, dialogue could occur among teacher educators regarding the teaching methods that best prepare preservice teachers to deliver SBAE's comprehensive, threecircle model in more integrated and complementary ways (Roberts \& Edwards, 2015). Such discussions should also involve service learning's place and relevance in the effective delivery of SBAE programs. In addition, implications may exist for informal and nonformal learning contexts, for example, in 4-H youth programming through cooperative extension programs.

Although agricultural education teacher educators appear to understand the benefits of service learning as a method of instruction, more work is needed to assist them with learning to navigate the challenges inherent to its use. To that aim, professional development sessions should specifically address issues such as lack of knowledge of service learning and time constraints, as perceived to be associated with implementing the method. Examples of course syllabi should be shared with AAAE members that demonstrate how to integrate service learning as an instructional approach in teaching methods courses. After considering examples of how the method is used to enrich teacher preparation by peers, agricultural education teacher educators may begin to make shifts in their practice. Further, teacher educators should be encouraged to reconsider the view that service learning will require additional time in their methods courses. Instead, they should be urged to consider service learning as a complement to their teacher preparation 
programs. For example, perhaps a service-based learning project serves as a capstone experience in teaching methods courses by which a majority of the assignments, such as lesson plan development and use, are connected to a larger service learning undertaking in their institutions' surrounding communities. Finally, agricultural education teacher educators should be encouraged to model the use of service learning so their preservice students' can observe and experience the method, including the creation of awareness, how-to, and principles knowledge presaging its adoption and practice (Rogers, 2003). Implementing these approaches could create opportunities for discussing the challenges SBAE instructors may encounter when using service learning in their teaching practice and how to overcome these challenges.

\section{References}

Ajzen, I. (1991). The theory of planned behavior. Organizational Behavior and Human Decisions Processes, 50(1), 179-211. https://doi.org/10.1016/0749-5978(91)90020-T

Ajzen, I. (2002). Constructing a theory of planned behavior questionnaire: Conceptual and methodological considerations. Amherst: University of Massachusetts System. Retrieved from http://www.people.umass.edu/aizen/pdf/tpb.measurement.pdf

Ajzen, I. (2006). Behavioral interventions based on the theory of planned behavior. Amherst: University of Massachusetts System. Retrieved from http://www.people.umass.edu/aizen/pdf/tpb.intervention.pdf

American Association for Agricultural Education. (2016). Membership information. Author. Retrieved from http://www.aaaeonline.org/join

Anderson, J. B. (2000). Learning in deed: Service-learning and preservice teacher education. Denver, CO: Education Commission of the States.

Anderson, J. B., \& Pickeral, T. (1998). Challenges and strategies for success with servicelearning in preservice teacher education. Omaha: University of Nebraska.

Armitage, C. J., \& Conner, M. (2001). Efficacy of the theory of planned behavior: A metaanalytic review. British Journal of Social Psychology, 40(4), 471-499. https://doi.org/10.1348/014466601164939

Ball, D., \& Geleta, N. (2012). A delicate balance: Service-learning in teacher education. Journal of the Scholarship of Teaching and Learning, 5(1), 1-17. Retrieved from http://files.eric.ed.gov/fulltext/EJ910337.pdf

Barnes, M. E. (2016). The student as teacher educator in service-learning. Journal of Experiential Education, 39(4), 238-253. https://doi.org/10.1177\%2F1053825916643831

Bates, A. J. (2009). Service learning as an instructional strategy for the preparation of teachers. Journal of Effective Teaching, 9(1), 5-23. Retrieved from http://files.eric.ed.gov/fulltext/EJ1092201.pdf

Birkenholz, R. J., \& Simonsen, J. C. (2011). Characteristics of distinguished programs of agricultural education. Journal of Agricultural Education, 52(3), 16-26. Retrieved from https://files.eric.ed.gov/fulltext/EJ956084.pdf

Bornmann, L., Mutz, R., \& Daniel, H. D. (2010). A reliability-generalization study of journal peer reviews: A multilevel meta-analysis of inter-rater reliability and its determinants. PLoS ONE, 5(12), 1-10. https://doi.org/10.1371/journal.pone.0014331

Bringle, R. G., \& Hatcher, J. A. (1995). A service-learning curriculum for faculty. Michigan Journal of Community Service Learning, 2(1), 112-122. Retrieved from http://hdl.handle.net/2027/spo.3239521.0002.111 
Butcher, J., Howard, P., Labone, E., Bailey, M., Groundwater, S., McFadden, . . \& \& Martinez, K. (2003). Teacher education, community service learning, and student efficacy for community engagement. Asia-Pacific Journal of Teacher Education, 31(1), 109-124. https://doi.org/10.1080/13598660301612

Butin, D. W. (2006). The limits of service-learning in higher education. The Review of Higher Education, 29(4), 473-498. Retreived from https://muse.jhu.edu/article/198714/summary

Butin, D. W. (2010). Service-learning in theory and practice: The future of community engagement in higher education. New York, NY: Palgrave.

Campus Compact. (2016). Presidents' declaration on the civic responsibility of higher education. Author. Retrieved from http://www.compact.org/presidential/declaration.html

Chambers, D. J., \& Lavery, S. (2012). Service-learning: A valuable component of pre-service teacher education. Australian Journal of Teacher Education, 37(4), 99-108. Retrieved from http://search.informit.com.au/documentSummary; dn= 767781 396834335;res=IELAPA

Chiaburu, D. S., \& Tekleab, A. G. (2005). Individual and contextual influences on multiple dimensions of training effectiveness. Journal of European Industrial Training, 29(8), 604626. https://doi.org/10.1108/03090590510627085

Chiu, T., Fang, D., Chen, J., Wang, Y., \& Jeris, C. (2001). A robust and scalable clustering algorithm for mixed type attributes in a large database environment. Proceedings of the 7th International Conference on Knowledge Discovery and Data Mining (pp. 263-268), San Francisco, CA.

Cipolle, S. B. (2010). Service-learning and social justice: Engaging students in social change. Lanham, MD: Rowman \& Littlefield Publishers.

Corbin, J., \& Strauss, A. (2015). Basics of qualitative research: Techniques and procedures for developing grounded theory (4th ed.). Thousand Oaks, CA: Sage.

Creswell, J. W., \& Plano Clark, V. L. (2011). Designing and conducting mixed methods research (2nd ed.). Thousand Oaks, CA: Sage.

Crews, R. J. (2002). Higher education service-learning: Sourcebook. Westport, CT: Oryx Press.

Croom, D. B. (2008). Development of the integrated three-component model of agricultural education. Journal of Agricultural Education, 49(1), 110-120. Retrieved from http://www.jae-online.org/attachments/article/140/Croom_49_1_110-120.pdf

Daniels, K., Patterson, G., \& Dunston, Y. (2010). Rules of engagement: A service learning pedagogy for preservice teacher education. Journal for Civic Commitment, 15(1), 1-16. Retrieved from https://www.mesacc.edu/community-civic-engagement/journals/rulesengagement-service-learning-pedagogy-pre-service-teacher

Dillman, D. A., Smyth, J. D., \& Christian, L. M. (2014). Internet, phone, mail, and mixed-mode surveys: The tailored design method (4th ed.). Hoboken, NJ: John Wiley \& Sons.

Eyler, J., \& Giles, D. E. (1999). Where's the learning in service-learning? San Francisco, CA: Jossey-Bass.

Field, A. (2013). Discovering statistics using IBM SPSS statistics (4th ed.). Thousand Oaks, CA: Sage.

Francis, J. J., Eccles, M. P., Johnston, M., Walker, A., Grimshaw, J., \& Foy, R. (2004). Constructing questionnaires based on the theory of planned behavior: A manual for health services researchers. Newcastle, UK: Centre for Health Services Research. Retrieved from http://openaccess.city.ac.uk/1735/

Fraser, J. W. (2014). The school in the United States: A documentary history (3rd ed.). New York, NY: Routledge. 
Gelmon, S. B., Holland, B. A., Driscoll, A., Spring, A., \& Kerrigan, S. (2001). Assessing service learning and civic engagement: Principles and techniques. Providence, RI: Campus Compact.

Hart, S. M., \& King, J. R. (2007). Service learning and literacy tutoring: Academic impact on preservice teachers. Teaching and Teacher Education, 23(4), 323-338. https://doi.org/10.1016/j.tate.2006.12.004

Hildenbrand, S. M., \& Schultz, S. M. (2015). Implementing service learning in pre-service teacher coursework. Journal of Experiential Education, 38(3), 262-279. https://doi.org/10.1177\%2F1053825915571748

Hou, S. I. (2010). Developing a faculty inventory measuring perceived service-learning benefits and barriers. Michigan Journal of Community Service Learning, 16(2), 78-89. Retrieved from http://hdl.handle.net/2027/spo.3239521.0016.206

Jenkins, C. C. III, \& Kitchel, T. (2010). Defining agricultural education instructional quality indicators. Journal of Agricultural Education, 51(3), 53-63. Retrived from http://www.jaeonline.org/attachments/article/85/Vol\%2051\%20No\%203\%20 pg\%2053\%20\%20Jenkins.pdf

Lake, V. E., \& Jones, I. (2008). Service-learning in early childhood teacher education: Using service to put meaning back into learning. Teaching and Teacher Education, 24(8), 2146-2156. https://doi.org/10.1016/j.tate.2008.05.003

Lincoln, Y. S., \& Guba, E. G. (1985). Naturalistic inquiry. Newbury Park, CA: Sage.

Linde, C. (2009). Working the past: Narrative and institutional memory. New York, NY: Oxford University Press.

Macia, L. (2015). Using clustering as a tool: Mixed methods in qualitative data analysis. The Qualitative Report, 20(7), 1083-1094. Retrieved from http://www.nova.edu/ssss/QR/QR20/7/macia3.pdf

McCarthy, A., \& Garavan, T. (2006). Postfeedback development perceptions: Applying the theory of planned behavior. Human Resource Development Quarterly, 17(3), 245-267. https://doi.org/10.1002/hrdq.1173

Miles, M. B., Huberman, A. M., \& Saldaña, J. (2014). Qualitative data analysis (3rd ed.). Thousand Oaks, CA: Sage.

Mooi, E., \& Sarstedt, M. (2010). Cluster analysis. New York, NY: Springer.

Morgan, D. L. (2007). Paradigms lost and pragmatism regained: Methodological implications of combining qualitative and quantitative methods. Journal of Mixed Methods Research, 1(1), 48-76. https://doi.org/10.1177\%2F2345678906292462

National Research Council. (1988). Understanding agriculture: New directions for education. Washington, DC: National Academy Press.

Rhee, M. (2012). Radical: Fighting to put students first. New York, NY: Harper.

Roberts, R., \& Edwards, M. C. (2015). Service-learning's ongoing journey as a method of instruction: Implications for school-based, agricultural education. Journal of Agricultural of Agricultural Education, 56(2), 217-233. Retrieved from http://www.jaeonline.org/attachments/article/1910/2014-0985\%20roberts.pdf

Roberts, R., \& Edwards, M. C. (2018). Imaging service-learning in The Agricultural Education Magazine from 1929-2009: Implications for the method's reframing and use. Journal of Agricultural Education, 59(3), 15-35. Retrieved from https://doi.org/10.5032/jae.2018.03015

Roberts, T. G., \& Dyer, J. E. (2004). Characteristics of effective agriculture teachers. Journal of Agricultural Education, 45(4), 82-95. Retrived from http://www.jaeonline.org/attachments/article/288/45-04-082.pdf

Rogers, E. M. (2003). Diffusion of innovations (5th ed.). New York, NY: The Free Press. 
Saldaña, J. (2012). The coding manual for qualitative researchers (2nd ed.). Thousand Oaks, CA: Sage.

Saltmarsh, J., \& Hartley, M. (2008). Democratic civic engagement: Higher education and democracy: The future of engagement. Boston, MA: New England Resource Center for Higher Education.

Speck, B. W., \& Hoppe, S. L. (2004). Service learning: History, theory, and issues. Westport, CT: Praeger Press.

Stake, R. E. (2006). Multiple case study analysis. New York, NY: Guilford Press.

Tatebe, J. (2013). Bridging gaps: Service learning in teacher education. Pastoral Care in Education, 31(3), 240-250. https://doi.org/10.1080/02643944.2013.774044

Teddlie, C., \& Yu, F. (2007). Mixed methods sampling: A typology with examples. Journal of Mixed Methods Research, 1(1), 77-100.

Tyack, D., Lowe, R., \& Hansford, E. (1984). Public schools in the hard times: The Great Depression and recent years. Cambridge, MA: Harvard University Press.

Whitehurst, G. J. (1984). Interrater agreement for journal manuscript reviews. American Psychologist, 39(1), 22-28. Retrived from https://psycnet.apa.org/record/1984-27067-001

Yang, F. Y., Chang, C. Y., \& Hsu, Y. S. (2008). Teacher views about constructivist instruction and personal epistemology: A national study in Taiwan. Educational Studies, 34(5), 527-542. https://doi.org/10.1080/03055690802288486 